\title{
Informed Consent in Surgical Practice in Port Harcourt: How Informed are the Patients?
}

\author{
Promise N. Wichendu, Rex Friday Ogoronte A. Ijah, Friday E. Aaron, Alexander A. Dimoko, \\ Joy O. Dayi, and Ebimie M. Eleke
}

\section{ABSTRACT}

\begin{abstract}
Aim: The aim of this study was to ascertain the opinion of patients on counselling of the surgical patient in tertiary healthcare facilities in Port Harcourt in the months of May and June 2020.
\end{abstract}

Background: Counseling of the surgical patient is a dynamic process and its scope which is individualized should arm the patient with information on the purpose and nature of the disease and treatment, etc.

Materials and Methods: Four hundred and twenty respondents were recruited for this cross-sectional descriptive study carried out in the wards and specialist surgical out-patient clinics of Teaching Hospitals in Port Harcourt, Nigeria between the months of May and June 2020 using semi-structured questionnaires. Data obtained was analysed using the Statistical Package for the Social Sciences (SPSS) version 20.0.

Results: Two hundred and twenty-five $(53.6 \%)$ respondents asserted that they had counselling sessions for the surgical operation, $108(25.7 \%)$ respondents opined that they did not have counselling session, while 87 $(20.7 \%)$ were not sure if they had or not. Forty-five $(\mathbf{1 0 . 7 \%})$ respondents asserted that the surgeons carried out the counselling. Only, $227(54.0 \%)$ of the respondents affirmed that they were satisfied with the counselling sessions, while $104(24.8 \%)$ respondents asserted that there was no counselling session at all.

Conclusion: The opinion of patients on the counselling service experience is not entirely satisfactory. There is need for closer attention to be paid to issues of counselling of the surgical patient in order to ensure the full benefits of the services rendered.

Keywords: surgical counselling, informed consent, patients' opinions, tertiary healthcare, Port Harcourt, Nigeria.

\section{INTRODUCTION}

Counselling of the surgical patient is dynamic and its scope which is individualized should arm the patient with information on the nature of the disease, purpose of the treatment, potential benefits and the risks involved, available alternatives and the possible effects of non-treatment [1]. In counselling the surgical patient, preconditions like competence or capacity, and voluntarism, information disclosure and understanding, and decisions must be included to guarantee an informed consent [2], [3]. Patients have expectations when they come to hospital with a surgical condition. The degree to which these expectations are met or otherwise could result in patient satisfaction or a hurtful feeling that may culminate into medicolegal actions. Instances of this has been reported in studies from several parts of the globe [4]-[7].
Published Online: July 14, 2021

ISSN: $2736-5476$

DOI: $10.24018 /$ ejclinicmed.2021.2.3.18

Promise N. Wichendu

Department of Surgery, University of Port Harcourt Teaching Hospital, Port Harcourt, Nigeria.

Rex Friday Ogoronte A. Ijah *

Department of Surgery, University of Port Harcourt Teaching Hospital, Port Harcourt, Nigeria.

(e-mail: rexijah@gmail.com)

Friday E. Aaron

Department of Surgery, Rivers State University Teaching Hospital, Port Harcourt, and Senior Lecturer, Rivers State University, Port Harcourt, Nigeria. Alexander A. Dimoko

Department of Surgery, University of Port Harcourt Teaching Hospital, Port Harcourt, Nigeria.

Joy O. Dayi

Department of Anesthesia, University of Port Harcourt Teaching Hospital, Port Harcourt, Nigeria.

Ebimie M. Eleke

Department of Education (Guidance and Counselling Unit), Faculty of Arts \& Education, University of Africa, ToruOrua, Sagbama Local Government Area, Bayelsa State, Nigeria.

*Corresponding Author
The surgical patient, depending on the surgical condition and comorbidities, is often attended to by a team of professional healthcare staff - surgeon, anesthetist, physicians, nurses (clinic, ward and perioperative), etc. - led by the surgeon who takes responsibility for the overall care of the patient. All the healthcare staff do render some form of counselling to the surgical patient, especially as it pertains to their field of specialization. However, it is expected that the fundamental issues of the surgical condition should be well communicated from the surgeon to the patient and or relatives (as the case may be) [8]. The nurses have more contact time with the patients and have been reported to counsel patients about their intended surgery [9]-[12] There is growing concern for patient centred care, which demands understanding of patients' individual needs, perspectives, and values from the health care providers. The surgeon is therefore required to provide the patients with information enough to build trust and 
participate in their care [13]. The surgical patient with oncologic conditions or a need for surgical excision of a limb or appendage requires more attention because of the additional physical and psychologic effect on the patient [14].

Sub-Saharan African countries have low patient-doctor ratio and bed to population ratio far below the recommended value by the World Health Organization [15], [16]. The implication of this is that the surgeon in the African context is saddled with the responsibility of attending to larger number of surgical patients, and hence would have to spend less amount of time and attention for each patient. This will necessarily impact negatively on the quality of counselling offered to the surgical patient. The issue is made worse by continuous migration of trained healthcare professionals to developed climes for reasons of better working conditions, training, better wages, prestige, and the desire to help family [17]. The aim of this study was to ascertain the opinion of patients on surgical counselling in tertiary healthcare facilities in Port Harcourt from the months of May to June 2020 , in terms of their experience of current practice, category of staff that carried out counseling, duration of counselling sessions, and satisfaction with the counselling.

\section{Methodology}

The study was carried out in the months of May and June 2020 at The University of Port Harcourt Teaching Hospital, and the Rivers State University Teaching Hospital - both are tertiary healthcare facilities in Port Harcourt, the capital of Rivers State, South-South of the Federal Republic of Nigeria. Surgeries performed in these government owned tertiary health facilities include but not limited to general surgical, neurosurgical, otorhinolaryngologic, dental/oralmaxillo-facial, plastic surgical, cardiothoracic, orthopedic, obstetric, and gynecologic, urologic, pediatric surgical, and laparoscopic surgical procedures.

Patients and their relatives constituted the study population for the cross-sectional descriptive study carried out in the wards and specialist surgical out-patient clinics of Teaching Hospitals. The minimum sample size of 400 used for the study (a survey) was determined using the formula developed by Yaro Yamen based on estimated population of 10,000 surgical patients. Using the formula:

$$
\mathrm{n}=\mathrm{N} /\left(1+\mathrm{Ne}^{2}\right),
$$

where $\mathrm{n}=$ minimum sample size;

$\mathrm{N}=$ Total population size;

$\mathrm{e}=$ desired precision/level of significance, usually $5 \%(0.05)$ at $95 \%$ Confidence Interval (CI).

All patients available at the point in time who gave their consent were included and given a semi-structured Questionnaires using the convenience sampling method. Data on demographics and current practice of counselling experienced by respondents were obtained and analyzed using the Statistical Package for the Social Sciences (SPSS) version 20.0 .

\section{RESULTS}

A total of 420 respondents were recruited for the study. The demographic characteristics of the respondents are presented in Table I. One hundred and thirty-two (31.4\%) respondents were males and female respondents were 288 $(68.6 \%)$. One hundred and three $(24.5 \%)$ respondents were less than 25 years, $214(51.0 \%)$ were between 25 - 40 years, and $91(21.7 \%)$ were between 41 and 60 years. One hundred and forty-nine $(35.5 \%)$ were singles, and 237 (56.4\%) were married. Three hundred and ninety-three (93.6\%) (88.4\%) respondents were Christians, and 27 (6.4\%) were Muslims.

TABLE I: SOCIO-DEMOGRAPHIC CHARACTERISTICS OF RESPONDENTS

\begin{tabular}{ccc}
\hline Variables & Frequency & Percentage \\
\hline Sex (Total) & 420 & 100 \\
Male & 132 & 31.4 \\
Female & 288 & 68.6 \\
Age (Total) & 420 & 100 \\
Less than 25 years & 103 & 24.5 \\
25-40 Years & 214 & 51.0 \\
41-60 years & 91 & 21.7 \\
Above 60 years & 12 & 2.9 \\
Marital Status (Total) & 420 & 100 \\
Single & 149 & 35.5 \\
Married & 237 & 56.4 \\
Separated & 13 & 3.1 \\
Divorced & 21 & 5.0 \\
Religion (Total) & 420 & 100 \\
Christianity & 393 & 93.6 \\
Islam & 27 & 6.4 \\
\hline
\end{tabular}

TABLE II: CURRENT PRACTICE OF COUNSELLING

\begin{tabular}{|c|c|c|}
\hline Variables & Frequency & Percentage \\
\hline $\begin{array}{l}\text { Respondent/Relative done surgical } \\
\text { operation in the past (Total) }\end{array}$ & 420 & 100 \\
\hline Yes & 265 & 63.1 \\
\hline No & 75 & 17.9 \\
\hline Don't know & 80 & 19.0 \\
\hline $\begin{array}{l}\text { Any counselling session for } \\
\text { respondents/relative (Total) }\end{array}$ & 420 & 100 \\
\hline Yes & 225 & 53.6 \\
\hline No & 108 & 25.7 \\
\hline Don't know & 87 & 20.7 \\
\hline $\begin{array}{c}\text { Category of staff that carries out } \\
\text { counselling (Total) }\end{array}$ & 420 & 100 \\
\hline The surgeon that did the operation & 45 & 10.7 \\
\hline $\begin{array}{l}\text { The anaesthetist (who made patient } \\
\text { not to feel pain) }\end{array}$ & 21 & 5.0 \\
\hline The Nurse & 63 & 15.0 \\
\hline All of the above & 149 & 35.5 \\
\hline None of the above & 31 & 7.4 \\
\hline Not Sure & 18 & 4.3 \\
\hline No counselling & 93 & 22.1 \\
\hline Time spent for the counselling (Total) & 420 & 100 \\
\hline Less than 5 minutes & 48 & 11.4 \\
\hline 5-10 minutes & 104 & 24.8 \\
\hline 11-30 minutes & 114 & 27.1 \\
\hline More than 30minutes & 25 & 6.0 \\
\hline Not Sure & 23 & 5.5 \\
\hline None & 106 & 25.2 \\
\hline Satisfied with the counselling (Total) & 420 & 100 \\
\hline Yes & 227 & 54.0 \\
\hline No & 38 & 9.0 \\
\hline Not sure & 51 & 12.1 \\
\hline No Counselling & 104 & 24.8 \\
\hline
\end{tabular}

Table II shows the opinion of patients on the current practice of counselling. Two hundred and sixty-three (63.1\%) respondents affirmed that they had undergone surgical operation in Port Harcourt, while 75 (17.9\%) had not. Two hundred and twenty-five $(53.6 \%)$ respondents asserted that they had counselling sessions for the surgical operation, $108(25.7 \%)$ respondents opined that they did not 
have counselling session, while $87(20.7 \%)$ were not sure if they had or not. The category of staff that conducted the counselling is shown in Table II. Forty-five (10.7\%) respondents asserted that the surgeons carried out the counselling, $21(5.0 \%)$ mentioned the anaesthetists, and 63 $(15.0 \%)$ opined that it was the nurses, while 149 (35.5\%) considered that all three categories of staff were involved in carrying out the counselling.

The duration of counselling session as reported by patient respondents is also shown in Table II. Forty-eight (11.4\%) respondents affirmed that counselling session duration was less than 5 minutes, 104 (24.8\%) felt that 5-10 minutes was spent, $114(27.4 \%)$ opined that it was only 11-30 minutes, and $25(6.0 \%)$ respondents mentioned more than 30 minutes. Additionally, $227(54.0 \%)$ of the respondents asserted that they were satisfied with the counselling sessions, $38(9.0 \%)$ were not satisfied, and $51(12.1 \%)$ were not sure. However, 104 (24.8\%) respondents asserted that there was no counselling session at all.

\section{DISCUSSION}

The necessity for counselling of surgical patients has been reported with emphasis on pre-admission, pre-surgical, postoperative, and pre-discharge counselling sessions [18]. This issue is still on the front burner with the persisting poor doctor-patient ratio in low-income countries. The opinion of the public, and in this instance the patients and their relatives, is critical to the success of health care service delivery [19]-[21]. The favourability (or otherwise) of their opinions determines further patronage and ease of relationship with the health institution [22]-[24]. The females were the majority among respondents. Part of the explanation for this could be that it is mostly women who are involved in home-making that accompany the sick to the hospital as relatives in the African setting, while the men stay back to source for fund for their care [25]-[28]. This traditional disposition is however fast changing [26], [29]. This is important because the study was carried out among patients and their accompanying relatives. The inclusion of patients' relatives in this study is justified in the sense that the varied burden of patients' illness may not allow them to remember much of the information relating to their care, therefore leaving the patients relatives to do that bit with the doctors. A little above half of the respondents were within 20-40 years of age. The majority Christian population of respondents is typical of the southern part of Nigeria with predominant Christian population.

About half of our respondents affirmed that they underwent counselling session during their surgical operation in Port Harcourt, a few asserted that they did not have counselling session, while others were uncertain. The possibilities are that they may have forgotten some details, however, this picture of patients' opinion on surgical counselling certainly does not leave an arbiter with the impression of an effective counselling service in Port Harcourt. Few respondents were of the opinion that all three categories of the surgery community (surgeons, anaesthetists, and nurses) were involved in carrying out the counselling in their last surgery, while much fewer asserted that the surgeons carried out the counselling. This second opinion picture of the respondents on counselling of the surgical patient also cannot market the current counselling service for distinction. A model of nurse-counselling service was described among comparison groups of breast cancer patients who had mastectomy and reported to result in less depression for the first 3 months postoperatively [30].

In family planning clinics, counselling session longer than 14 minutes has been reported to have little advantage on effectiveness of the counselling process [31]. A randomized controlled trial describing innovative psychotherapy program for surgical patients, varied counselling duration was reported depending on individual patient needs and usually not exceeding 50 minutes [32]. The duration of counselling session as reported by patient respondents varied widely from less than 5 minutes to just above 30 minutes. Although a little more than half of the total respondents attested to being satisfied with their counselling session, others felt that counselling session did not take place, hence satisfaction could not be mentioned. The latter opinion of few others appears to be an expression of disgust at the supposed counselling service. The implication of this is that little attention is paid to surgical counselling sessions, leaving some patients and relatives unsatisfied with health service delivery. However, variable the duration, investing sufficient time to counselling patients could avoid unnecessary medicolegal issues [4], [5].

Our findings share some similarity with another study done in Calabar Nigeria reporting counselling for ophthalmic services, though in that study the counselling was carried out by social workers with higher satisfaction among patients [33]. Our study differs from another study that described quality of counselling services among knee or shoulder arthroscopy patients and reported satisfaction among almost all respondents, with a call for caregivers training in patient-centred and goal-oriented counselling [7]. Also, satisfaction among patients who underwent laryngectomies and primary voice restoration was reported to be high, though counselling in this study was carried out by multiple counsellors [34]. Efficacy of counselling on service satisfaction of surgical patients have been reported in numerous other studies [35]-[37].

The opinion of patients on the counselling service experience is not entirely satisfactory. Issues at stake include variability of the counselling session duration with some being as low as less than 5-10 minutes, the category of staff to be vested with the responsibility of counselling, and the consequent patient satisfaction with services rendered. There is need for closer attention to be paid to issues of counselling of the surgical patient in order to ensure the full benefits of the services rendered. There is need to incorporate this key subject in undergraduate and postgraduate curriculum to give practitioners a good orientation in this area.

\section{ACKNOWLEDGEMENT}

We acknowledge the contributions of the surgery departmental ward and clinic nurses of the hospital (University of Port Harcourt Teaching Hospital) who graciously helped with some sample collection for the study.

Ethical Considerations: The approval of the Research 
Ethics Committee of the University of Port Harcourt Teaching Hospital and the Rivers State University Teaching Hospital were obtained before commencement of study.

\section{FUNDING}

The Study was privately sponsored by the researchers.

\section{REFERENCES}

[1] Ward, E., T. Hobson, and A. Conroy, Pre-and post-operative counselling and information dissemination: perceptions of patients undergoing laryngeal surgery and their spouses. Asia Pacific Journal of Speech, Language and Hearing, 2003. 8(1): p. 44-68.

[2] Berg, J.W., et al., Informed consent: legal theory and clinical practice. 2001: Oxford University Press.

[3] Section, U.v.A.H.L., Promotion of the Rights of Patients in Europe: Proceedings of a WHO Consultation. 1995: Kluwer Law International.

[4] Rakhonde, A.K., et al., A prospective study of level of satisfaction among surgical patients in a tertiary care hospital of central India. International Surgery Journal, 2016. 2(4): p. 499-504.

[5] Meredith, P. and C. Wood, Aspects of patient satisfaction with communication in surgical care: confirming qualitative feedback through quantitative methods. International Journal for Quality in Health Care, 1996. 8(3): p. 253-264.

[6] Akin-Olugbade, O., et al., Determinants of patient satisfaction following penile prosthesis surgery. The journal of sexual medicine, 2006. 3(4): p. 743-748.

[7] Kaakinen, P., H. Ervasti, and M. Kääriäinen, Quality of counselling for knee and shoulder arthroscopy patients during day surgery. International journal of orthopaedic and trauma nursing, 2017. 24: p. 12-20.

[8] Levinson, W. and N. Chaumeton, Communication between surgeons and patients in routine office visits. Surgery, 1999. 125(2): p. 127134.

[9] Kettunen, T., M. Poskiparta, and L. Liimatainen, Empowering counseling - a case study: nurse-patient encounter in a hospital. Health Education Research, 2001. 16(2): p. 227-238.

[10] Suhonen, R. and H. Leino-Kilpi, Adult surgical patients and the information provided to them by nurses: a literature review. Patient education and counseling, 2006. 61(1): p. 5-15.

[11] Lipponen, K., H. Kyngäs, and M. Kääriäinen, Surgical nurses readiness for patient counselling. Journal of Orthopaedic Nursing, 2006. 10(4): p. 221-227.

[12] Kettunen, T., M. Poskiparta, and M. Gerlander, Nurse-patient power relationship: preliminary evidence of patients' power messages. Patient Education and Counseling, 2002. 47(2): p. 101-113.

[13] Levinson, W., C.S. Lesser, and R.M. Epstein, Developing physician communication skills for patient-centered care. Health affairs, 2010. 29(7): p. 1310-1318.

[14] Nestel, D., et al., Communication challenges in surgical oncology. Surgical oncology, 2011. 20(3): p. 155-161.

[15] Opoku, S.Y., M. Benwell, and J. Yarney, Knowledge, attitudes, beliefs, behaviour and breast cancer screening practices in Ghana, West Africa. Pan African Medical Journal, 2012. 11(1).
[16] Nwaopara, A., Doctor to patient ratio and infrastructure gap in a psychiatric hospital in oil rich Eket, Nigeria. International Journal of Basic, Applied and Innovative Research, 2015. 4(3): p. 72-85.

[17] Toma, G., African Healthcare Exodus. Triple Helix, 2005: p. 12-13.

[18] Raju, B. and K. Reddy, Are counseling services necessary for the surgical patients and their family members during hospitalization? Journal of neurosciences in rural practice, 2017. 8(01): p. 114-117.

[19] Black, N. and C. Jenkinson, Measuring patients' experiences and outcomes. Bmj, 2009. 339: p. b2495.

[20] Garratt, A., E. Solheim, and K. Danielsen, National and cross-national surveys of patient experiences: a structured review [Internet]. 2008.

[21] Ponsignon, F., A. Smart, and L. Phillips, A customer journey perspective on service delivery system design: insights from healthcare. International Journal of Quality \& Reliability Management, 2018.

[22] Yu, T.-K., et al., The Impact of Service Recovery On Re-Patronage Behavioral Intentions: A Case Of The Health Center. 2010.

[23] [23] Jacobs, L.R., Institutions and culture: Health policy and public opinion in the US and Britain. World Politics: A Quarterly Journal of International Relations, 1992: p. 179-209.

[24] Bratton, M., R. Mattes, and E. Gyimah-Boadi, Public opinion, democracy, and market reform in Africa. 2005: Cambridge University Press.

[25] Varga, C.A., How gender roles influence sexual and reproductive health among South African adolescents. Studies in family planning, 2003. 34(3): p. 160-172.

[26] Jardine, S.A. and A. Dallalfar, Sex and gender roles: examining gender dynamics in the context of African American Families. Journal of Pedagogy, Pluralism, and Practice, 2012. 4(4): p. 18.

[27] Abrams, J., Blurring the lines of traditional gender roles: Beliefs of African American women. 2012.

[28] Strobel, M., African women. Signs: Journal of Women in Culture and Society, 1982. 8(1): p. 109-131.

[29] Fuest, V., 'This is the Time to get in Front': Changing Roles and Opportunities for Women in Liberia. African Affairs, 2008. 107(427): p. 201-224.

[30] Watson, M., et al., Counselling breast cancer patients: a specialist nurse service. Counselling Psychology Quarterly, 1988. 1(1): p. 2534.

[31] León, F.R., et al., Length of counseling sessions and the amount of relevant information exchanged: a study in Peruvian clinics. International Family Planning Perspectives, 2001: p. 28-46.

[32] Krampe, H., et al., Readiness to change and therapy outcomes of an innovative psychotherapy program for surgical patients: results from a randomized controlled trial. BMC psychiatry, 2017. 17(1): p. 417.

[33] Etim, B., et al., Patients' satisfaction with ophthalmic counselling services in a tertiary hospital in Calabar, South-South Nigeria. Ghana Medical Journal, 2020. 54(2): p. 76-81.

[34] Craven, A. and R. West, Counselling and care of laryngectomees: a preliminary study. International Journal of Language \& Communication Disorders, 1987. 22(3): p. 237-243.

[35] Maguire, P., et al., The effect of counselling on physical disability and social recovery after mastectomy. Clinical oncology, 1983. 9(4): p. 319-324.

[36] Wasteson, E., et al., High satisfaction rate ten years after bilateral prophylactic mastectomy-a longitudinal study. European journal of cancer care, 2011. 20(4): p. 508-513.

[37] Bresser, P.J., et al., Satisfaction with prophylactic mastectomy and breast reconstruction in genetically predisposed women. Plastic and reconstructive surgery, 2006. 117(6): p. 1675-1682. 